\title{
The translation inhibitor anisomycin induces Elk-1-mediated transcriptional activation of egr-1 through multiple mitogen-activated protein kinase pathways
}

\author{
Soon Young Shin', Joon Ho Lee', \\ Byung Wook $\mathrm{Min}^{2}$ and Young Han Lee ${ }^{1,3}$ \\ ${ }^{1}$ Division of Molecular and Life Sciences \\ College of Science and Technology \\ Hanyang University \\ Ansan 426-791, Korea \\ ${ }^{2}$ Department of Surgery \\ Korea University College of Medicine \\ Ansan 425-707, Korea \\ ${ }^{3}$ Corresponding author: Tel, 82-31-400-5517; \\ Fax, 82-31-416-9781; E-mail, younghan@hanyang.ac.kr
}

Accepted 3 November 2006

Abbreviations: ANX, anisomycin; CHX, cycloheximide; $\mathrm{P}_{\text {egr-1 }}$, egr-1 gene promoter

\begin{abstract}
The early growth response-1 gene (egr-1) encodes a zinc-finger transcription factor Egr-1 and is rapidly inducible by a variety of extracellular stimuli. Anisomycin (ANX), a protein synthesis inhibitor, stimulates mitogen-activated protein kinase (MAPK) pathways and thereby causes a rapid induction of immediate-early response genes. We found that anisomycin treatment of U87MG glioma cells resulted in a marked, time-dependent increase in levels of Egr-1 protein. The results of Northern blot analysis and reporter gene assay of egr-1 gene promoter $\left(P_{\text {egr- }-1}\right)$ activity indicate that the ANXinduced increase in Egr-1 occurs at the transcriptional level. Deletion of the serum response element (SRE) in the 5'-flanking region of egr-1 gene abolished ANX-induced $P_{\text {egr-1 }}$ activity. ANX induced the phosphorylation of the ERK1/2, JNK, and p38 MAPKs in a time-dependent manner and also induced transactivation of Gal4-Elk-1, suggesting that Elk-1 is involved in SRE-mediated egr-1 transcription. Transient transfection of dominant-negative constructs of MAPK pathways blocked ANX-induced $P_{\text {egr-1 }}$ activity. Furthermore, pretreatment with specific MAPK pathway inhibitors, including the MEK inhibitor U0126, the JNK inhibitor SP600125, and the p38 kinase inhibitor SB202190, completely
\end{abstract}

inhibited ANX-inducible expression of Egr-1. Taken together, these results suggest that all three MAPK pathways play a crucial role in ANX-induced transcriptional activation of $P_{\text {egr-1 }}$ through SRE-mediated transactivation of Elk-1.

Keywords: anisomycin; cycloheximide; early growth response protein 1; ets-domain protein Elk-1; mitogenactivated protein kinases; serum response element

\section{Introduction}

The egr-1 gene, which is also known as G0S30, NGFI-A, zif268, krox24, and Tis8, encodes a zincfinger-containing transcription factor and is an immediate-early response gene that is rapidly induced by stress, injury, mitogens, and differentiation factors in diverse cell types (Forsdyke, 1985; Sukhatme et al., 1988; Edwards et al., 1991; Liu et al., 1998). Egr-1 regulates the expression of genes that are involved in growth control and apoptosis by transactivating p21, p53, PTEN, TGF- $\beta 1$, fibronectin, and Gadd45 (Liu et al., 1998; Virolle et al., 2001; Krones-Herzig et al., 2003; Ragione et al., 2003; Thyss et al., 2005; Baron et al., 2006). Expression of Egr-1 in several tumor cells is low (Huang et al., 1997), and the ectopic expression of egr-1 in tumor cells attenuates cell proliferation and tumorigenicity and increases cell attachment (de Belle et al., 1999; Liu et al., $1999 ; 2000)$. These results suggest that Egr-1 plays a key role in the regulation of cell growth and death in response to mitogens and stress signals.

Extracellular growth factors such as EGF, FGF, and PDGF cause the rapid and transient transcriptional induction of egr-1. This induction is mediated in part by the serum response element (SRE) in the 5'-flanking region of the gene (Christy and Nathans, 1989; Clarkson et al., 1999; Tsai et al., 2000). The ternary complex factor (TCF) forms a ternary complex on the egr-1 SRE with the MADS (MCM1-agamous-ARG80-deficiens-SRF)-box protein serum response factor (SRF) (Treisman, 1994; Sharrocks, 2002). The TCFs represent a subfamily of Ets-domain transcription factors that contains at least three members, Elk-1 (Rao et al., 1989), Sap-1 (Dalton and Treisman, 1992), and Sap-2/Net/Erp (Dalton and Treisman, 1992; Lopez et al., 1994). 
Mitogen-activated protein kinase (MAPK) pathways play major roles in the transduction of mitogenic and stress stimuli into nuclear responses. The TCFs are known targets of the three major MAPKs, extracellular signal-regulated kinase (ERK), c-Jun $\mathrm{N}$-terminal kinase (JNK), and p38 kinase, and TCF phosphorylation by MAPKs causes an increase in SRE-mediated transcriptional activation (Price et al., 1995; Sharrocks, 2002). ERK-mediated phosphorylation of Elk-1 has been well established as correlating with increased transcriptional activation of egr-1 (Hipskind et al., 1994; Watson et al., 1997; Hodge et al., 1998; Guha et al., 2001; Schratt et al., 2001). In general, the ERK cascade is activated by growth factors and mitogens, whereas the JNK and p38 kinase cascades respond to cytokines and stress stimuli.

Inhibition of protein synthesis in Rat1 fibroblasts has been reported to induce transcriptional activation of egr-1 (Shin et al., 2002), and we have also observed that treatment of $3 \mathrm{Y} 1$ fibroblasts with cycloheximide $(\mathrm{CHX})$, a protein synthesis inhibitor, is sufficient to increase the transcriptional rate of egr-1 (Shin et al., 2002). The translation inhibitor anisomycin (ANX) induces c-fos gene expression by stimulating MAPK signaling (Zinck et al., 1995; Barros et al., 1997), suggesting that ANX is able to modulate intracellular signaling pathways, independently of a block to translation. However, the signaling process whereby de novo inhibition of translation stimulates egr-1 transcription has not been fully elucidated.

In the present study, we investigated the effects of the translation inhibitors ANX and $\mathrm{CHX}$ on the induction of egr-1 transcription in U87MG human glioma cells. We show that the SRE of egr-1 mediates the induction of egr-1 transcription by ANX. Moreover, we present evidence that all three major MAPK cascades, ERK1/2, JNK1/2, and p38 kinase, play important roles in ANX-induced Elk-1 transactivation, which in turn stimulates transcription of the egr-1 gene.

\section{Materials and Methods}

\section{Reagents}

DMEM and LipofectAMINE 2000 were purchased from Life Technologies, Inc. (Gaithersburg, MD), and fetal bovine serum was from Hyclone (Logan, Utah). Anisomycin, cycloheximide, U0126, SP600125, and SB202190 were obtained from Calbiochem (San Diego, CA). Antibodies against phospho-ERK1/2 (Thr202/Tyr204), phospho-JNK1/2 (Thr183/Tyr185), phospho-p38 (Thr180/Tyr182), and p38 MAPK were purchased from New England BioLabs (Beverly, MA). Antibodies against Egr-1, ERK2, JNK1 and GAPDH were from Santa Cruz Biotechnology (Santa Cruz, CA).

\section{Cell culture}

U87MG human glioma cells were maintained in DMEM (Life Technologies, Inc.) supplemented with $10 \%$ fetal bovine serum as described previously (Ahn et al., 2006). To investigate the effects of protein synthesis inhibitors, U87MG cells were starved in DMEM containing $0.5 \% \mathrm{FBS}$ for $24 \mathrm{~h}$, and then stimulated with ANX or $\mathrm{CHX}$ for various lengths of time, as indicated.

\section{Plasmids}

The serial deletion mutant constructs of the egr-1 promoter expressing the firefly luciferase were provided by Dr. H. Eibel (Department of Orthopedic Surgery, Research Laboratory University of Tubingen Medical Center, Germany) and described elsewhere (Aicher et al., 1999). pCMV/ $\beta$-gal plasmid for normalization of transfection efficiency was obtained from Clontech. Dominant-negative MEK1 (pCGN1/DNMEK1), dominant negative ERK2 (pHAERK2 K52R), dominant negative JNK1 (pSR $\alpha / \mathrm{HA}$ JNK T183A/Y185F), and kinase-dead p38 kinase (pcDNA3/flag-p38 T180A/Y182F) plasmids were kindly gifted by Dr. Min, DS (Pusan National University). Trans- and cis-acting reporter plasmids, pFR-Luc, pFA2-Elk1 and pSRF-Luc, were obtained from Stratagen (La Jolla, CA).

\section{Western blot analysis}

Cells were lysed as described previously (Kim et al., 2006), and $20-\mu \mathrm{g}$ aliquots of lysate were subjected to $10 \%$ SDS-polyacrylamide gel electrophoresis. The separated proteins were transferred to nitrocellulose filters that were incubated with primary antibodies and developed with the ECL detection system (Amersham Pharmacia Biotech., Piscataway, NJ). In some experiments, blots were reprobed with anti-GAPDH antibody for use as an internal control.

\section{egr-1 promoter assay}

U87MG glioma cells were seeded into $35-\mathrm{mm}$ dishes $\left(6 \times 10^{5}\right.$ cells/dish) and co-transfected with $0.5 \mu \mathrm{g}$ of 5 -deletion constructs of the egr-1 promoter $\left(P_{\text {egr-1 }}\right)$ (Aicher et al., 1999) and $0.2 \mu \mathrm{g}$ of the plasmid pCMV/ $\beta$-gal using LipofectAMINE 2000 reagents (Life Technologies, Inc.) according to the manufacturer's instructions. Where indicated, $0.5 \mu \mathrm{g}$ of a mammalian expression vector encoding dominantnegative (dn)-MEK1, dn-ERK2, dn-JNK1, or kinasedead (kd)-p38 kinase was included. Twenty-four hours post-transfection, cells were treated with ANX $(10 \mathrm{ng} / \mathrm{ml})$. Cells were harvested after $6-12 \mathrm{~h}$, protein extracts were prepared using Reporter lysis buffer 
(Promega), and 1-5 $\mu \mathrm{g}$ of protein was assayed for luciferase activity. Luminescence was measured using a luminometer (model TD 2020; Berthold, Tubingen, Germany).

\section{Transactivation assay}

pFA2-Elk1 encodes a fusion protein consisting of the yeast Gal4 DNA-binding domain (aa 1-147) and the activation domain of Elk-1 (aa 307-427). pFR-Luc contains five repeats of the Gal4-binding element upstream of a luciferase reporter gene. The transacting activity of Elk-1 was measured in U87MG cells using a luciferase reporter assay after the cells were co-transfected with $0.5 \mu \mathrm{g}$ of the trans-activator plasmid pFA2-Elk1 and $50 \mathrm{ng}$ of the luciferase reporter plasmid $p F R$-Luc. To assay SRF-dependent transcriptional activation, we used plasmid pSRFLuc, which contains five tandem repeats of the SRF-binding sequence. After transfection, cells were treated with or without ANX, as indicated, and assayed for luciferase activity.

\section{Results}

\section{Translation inhibitors induce expression of Egr-1 protein}

$\mathrm{CHX}$ inhibits protein synthesis by blocking the peptidyl synthase activity of eukaryotic ribosomes (Dieci et al., 1995; Christner et al., 1999), whereas ANX inhibits translation by binding to the 605 ribosomal subunit and blocking formation of peptide bonds (Barbacid and Vazquez, 1974). We have previously shown that $\mathrm{CHX}$ at low concentrations $(0.1-1 \mu \mathrm{g} / \mathrm{ml})$, but not at high concentrations $(>10$ $\mu \mathrm{g} / \mathrm{ml}$ ), causes accumulation of egr-1 mRNA in $3 Y 1$ fibroblasts by increasing the rate of egr-1 transcription rather than by stabilizing the egr-1 mRNA (Shin et al., 2002). To determine whether other protein synthesis inhibitor ANX activates egr-1 trans- cription, we examined the efficacy of $\mathrm{CHX}$ and ANX on Egr-1 expression in human U87MG glioma cells. When serum-starved U87MG cells were treated with $0.1 \mu \mathrm{g} / \mathrm{ml} \mathrm{CHX}$, the amount of Egr-1 protein increased within $1 \mathrm{~h}$ and reached a peak at $2 \mathrm{~h}$, after which the Egr-1 level dropped considerably (Figure 1A). ANX treatment at $10 \mathrm{ng} / \mathrm{ml}$ also markedly increased the amount of Egr-1 protein, but at $>50$ $\mathrm{ng} / \mathrm{ml}$, the amount of Egr-1 protein decreased dramatically, so that the Egr-1 level was only slightly higher than it was in untreated cells (Figure 1B). This result suggests that only a narrow concentration range of ANX is effective at increasing Egr-1 expression. A time-course study showed that ANX increased the level of Egr-1 protein within $2 \mathrm{~h}$; the level peaked at $4 \mathrm{~h}$ and then substantially decreased by $6 \mathrm{~h}$ (Figure 1C). In contrast, ANX did not affect the amount of GAPDH protein in the cells.

\section{SRE regions are essential for anisomycin-induced activation of egr-1 transcription}

To examine whether ANX causes accumulation of Egr-1 protein by increasing the egr-1 transcription rate, U87MG cells were transfected with $P_{\text {egr-1 }}$ plasmid containing an egr-1 promoter-controlled luciferase reporter gene. As shown in Figure 2A, treatment with ANX significantly increased egr-1 promoter activity to $1.7 \pm 0.3$-fold $(n=3), 1.9 \pm$ 0.3 -fold $(n=3)$, and $1.4 \pm 0.2$-fold $(n=3)$ at 5,10 , and $20 \mathrm{ng} / \mathrm{ml}$, respectively, as compared to untreated cells, demonstrating that ANX activates the transcription of the egr-1 gene. To further dissect the response element responsible for the ANX-induced activation of $P_{\text {egr- } 1}$, internal deletion mutants of $P_{\text {egr-1 }}$ (Aicher et al., 1999) were transfected into U87MG cells. Deletion of the proximal SRE5 ( $\delta S R E 5,-89$ to -108 ), a cluster of three SRES ( $\delta S R E 2-4,-326$ to -376), or the distal SRE1 ( $\delta S R E 1,-394$ to -410) resulted in complete loss of ANX-induced activation of the mutant $\mathrm{P}_{\text {egr-1 }}$, compared with the wild-type
A

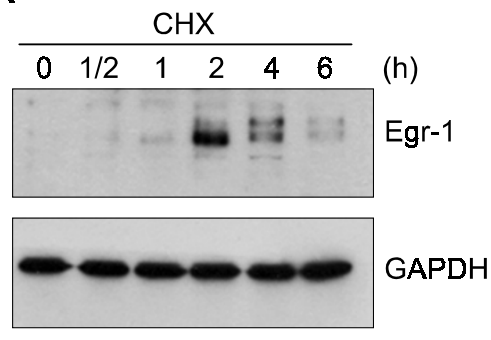

B

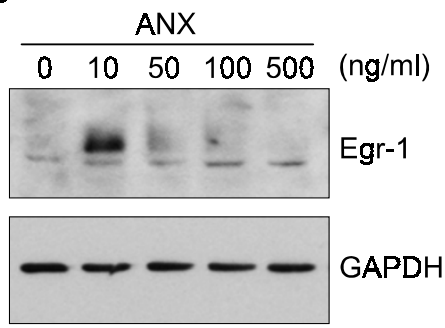

C

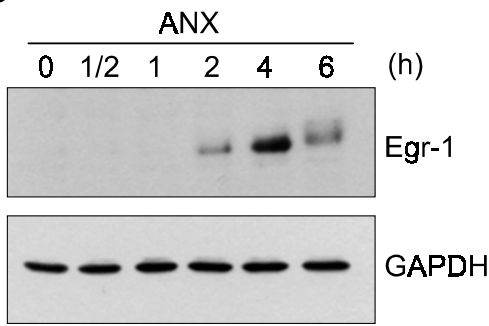

Figure 1. Effect of translation inhibitors on Egr-1 expression in U87MG cells. Serum-starved U87MG cells were exposed to $1 \mu \mathrm{g} / \mathrm{ml} \mathrm{CHX}(\mathrm{A})$ or 10 $\mathrm{ng} / \mathrm{ml}$ ANX (C) for various lengths of time, or were exposed to various concentrations of ANX for $2 \mathrm{~h}(\mathrm{~B})$. Protein lysates were prepared and were then analyzed by Western blotting using an anti-Egr-1 antibody. GAPDH was used as an internal control. Similar results were obtained in two other independent experiments. 
(WT) $P_{\text {egr-1 }}$. However, at present, we cannot explain the reason why either deletion of SRE regions completely abrogates the ANX response. Further studies will be required whether SRE binding proteins including co-activator/co-repressor cooperate among them. In contrast, deletion of the proximal cAMP-response element (CRE) 2 ( $\delta C R E 2,-127$ to -134$)$, the distal CRE1 ( $\delta C R E 1,-623$ to -630 ), or the Egr-1 binding sites ( $\delta E B S 1,-685$ to $-695 ; \delta E B S 2,-589$ to -597 )

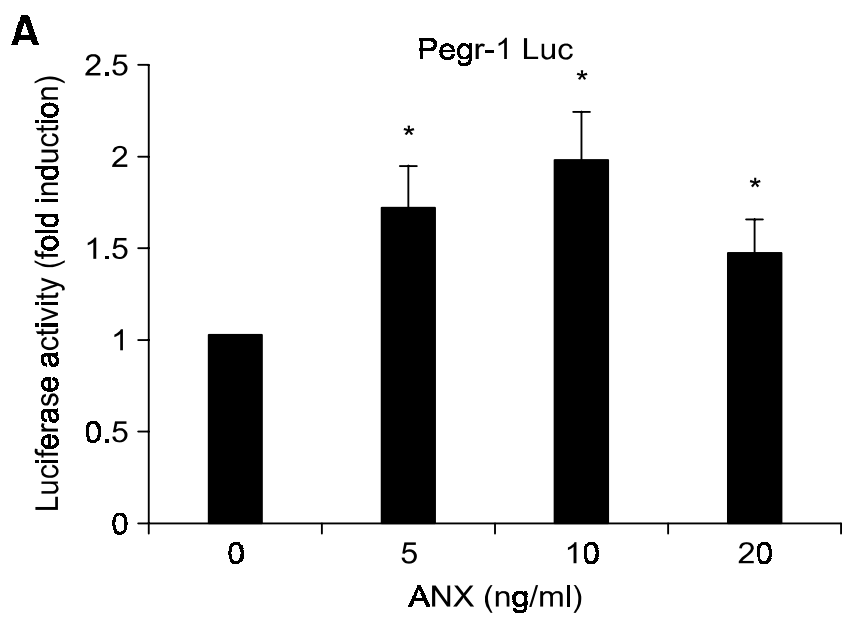

B

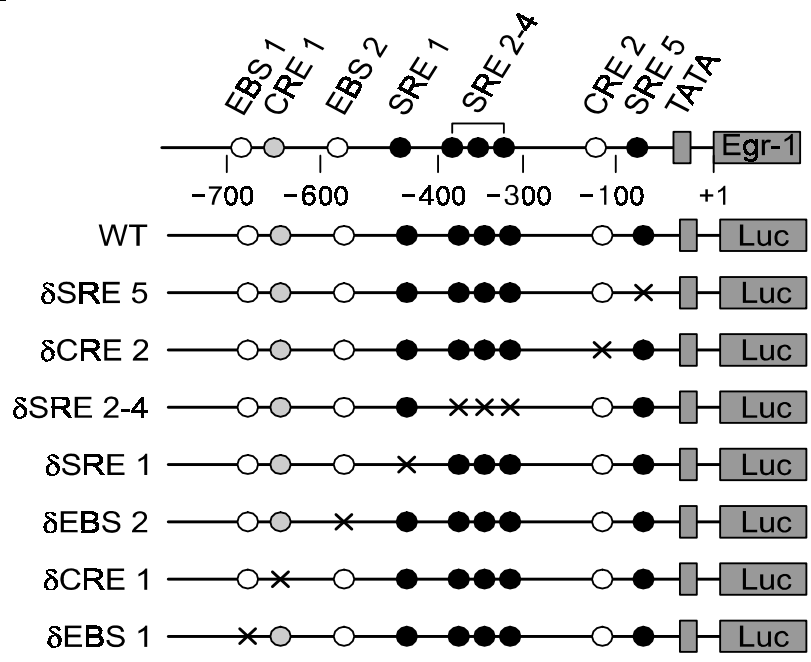

resulted in both a high basal level of reporter gene activity and in strong ANX-induced reporter gene activity, suggesting that the $C R E$ and EBS regions are negative regulators of Egr-1 expression. These results demonstrate that SRE regions are essential for ANX-induced activation of $P_{\text {egr- } 1 \text {. }}$.

\section{Anisomycin stimulates Elk-1 transactivation}

Elk-1 is a ternary complex factor (TCF) that forms a complex with the serum response factor (SRF) on the SRE of $\mathrm{P}_{\text {egr-1 }}$ and plays a crucial role in growth factor induction of egr-1 transcription (Chen et al., 2004). To assess whether Elk-1 is transactivated in response to ANX treatment, we utilized a transacting reporter assay system. U87MG cells were co-transfected with Gal4-Elk-1 DNA and plasmid pFR-Luc. Gal4-Elk-1 encodes a protein consisting of the yeast Gal4 DNA-binding domain fused to the activation domain of Elk-1 (aa 307-428), and pFRLuc contains five repeats of the Gal4-binding element upstream of a luciferase reporter gene. Treatment of cells with $10 \mathrm{ng} / \mathrm{ml}$ ANX resulted in an increase of Gal4-Elk-1 transactivation approximately 2.5-fold compared with that of untreated control cells (Figure 3A). To determine whether ANX stimulates SRF-dependent transcriptional activation, pSRF-Luc containing five tandem repeats of the SRF-binding sequence was used instead of pFR-Luc. In this case, ANX had no effect on SRF transactivation (Figure

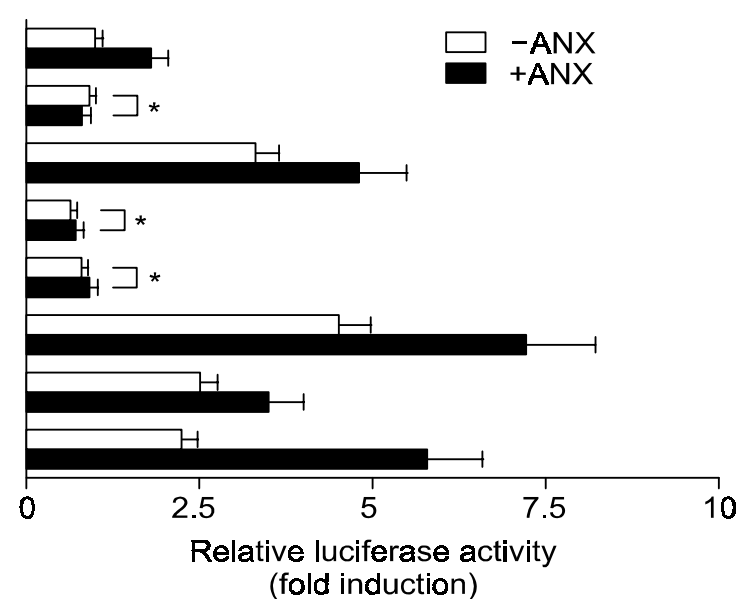

Figure 2. Effect of ANX on transcription of egr-1. U87MG cells were transfected with a wild-type $P_{\text {egr-1 }}-$ luciferase reporter gene construct. (A) After 24 $\mathrm{h}$ of transfection, cells were treated with $0,5,10$, or $20 \mathrm{ng} / \mathrm{ml}$ ANX for $6 \mathrm{~h}$. The cells were then lysed, and the lysates were analyzed for luciferase

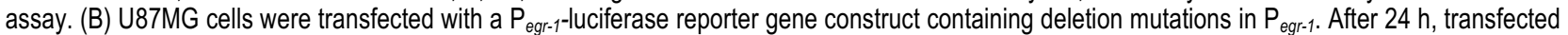
cells were treated with 0 or $10 \mathrm{ng} / \mathrm{ml}$ ANX for $6 \mathrm{~h}$, and luciferase assays were conducted. In both (A) and (B), the results are expressed as fold increase \pm S.D. of three independent experiments performed in triplicate, and are normalized for transfection efficiency using the pCMV/ $\beta$-gal reporter gene as a control. The statistical significance of the assays was evaluated using the Student's $t$-test $\left(^{*}, P<0.01\right.$ compared with untreated control cells). 
A

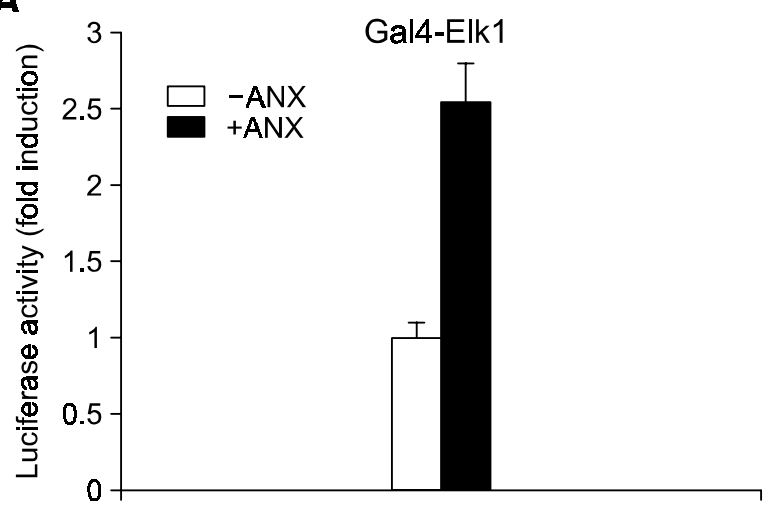

B

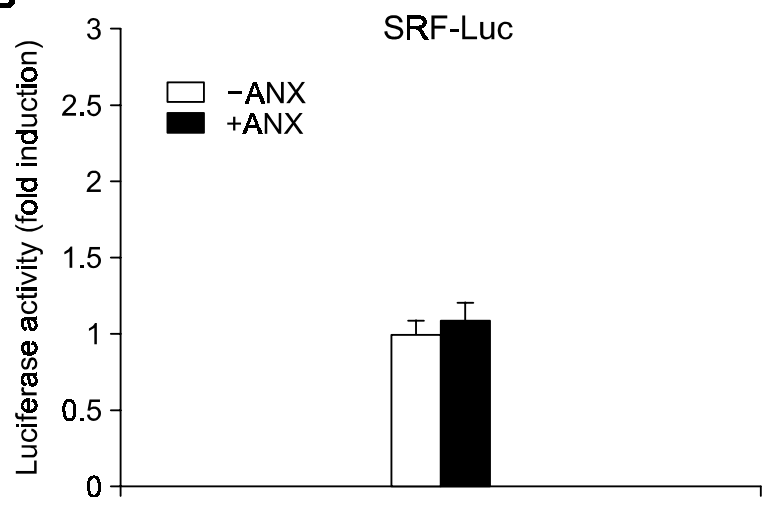

Figure 3. Effect of ANX on the trans-acting activity of Elk-1. U87MG cells were transfected with (A) plasmids pFA2/Gal4-Elk1 (50 ng) and pFR-Luc $(0.5 \mu \mathrm{g})$, or $(\mathrm{B})$ plasmid pSRF-Luc $(0.5 \mu \mathrm{g})$, which contains five tandem repeats of the SRF-binding sequence. After $24 \mathrm{~h}$ of transfection, the cells were treated with 0 or $10 \mathrm{ng} / \mathrm{ml}$ ANX for $12 \mathrm{~h}$, and then assayed for luciferase activity. The results are expressed as fold increase \pm S.D. of three independent experiments performed in triplicate, and are normalized for transfection efficiency using the $\mathrm{PCMV} / \beta$-gal reporter plasmid as a control.

A

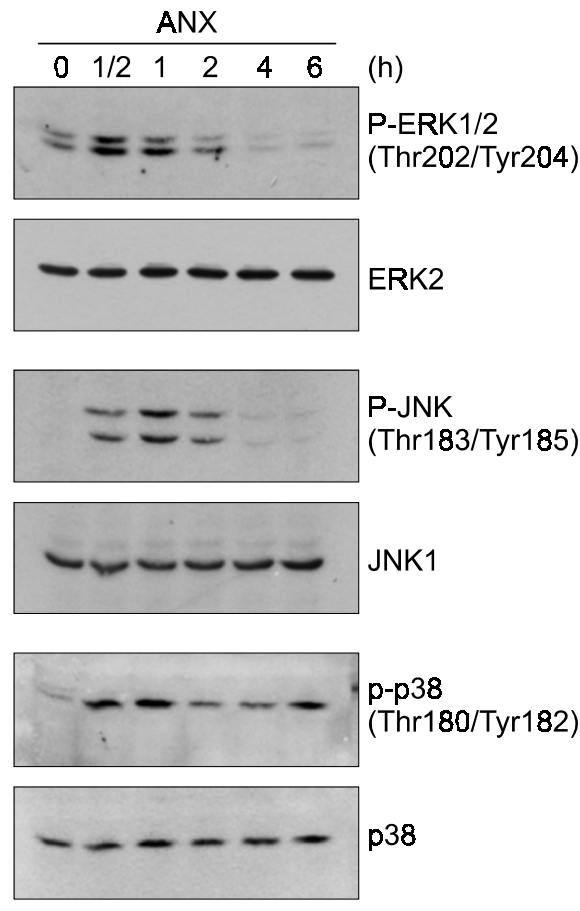

B

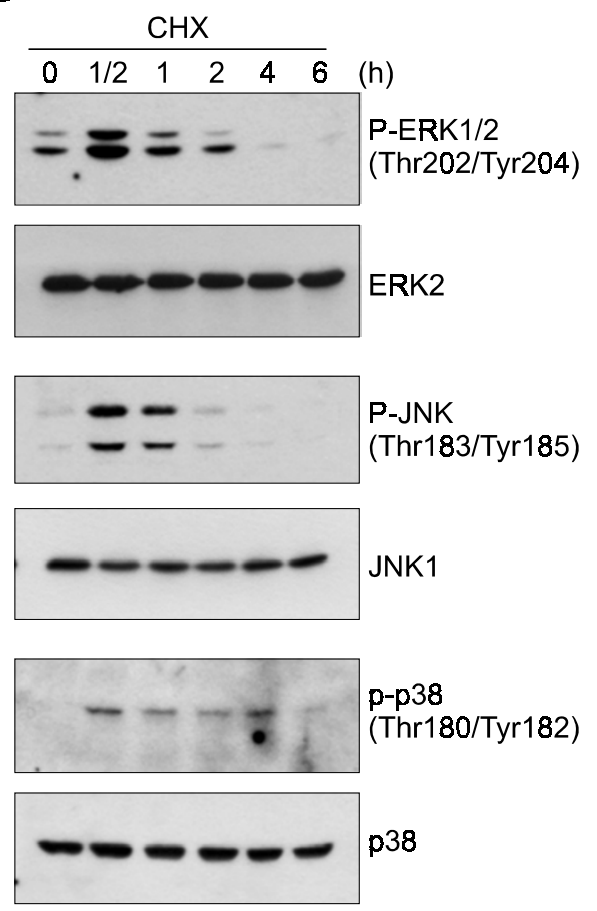

Figure 4. Activation of multiple MAPKs by ANX and CHX. Serum-starved U87MG cells were exposed to 10 $\mathrm{ng} / \mathrm{ml}$ ANX (A) or $1 \mu \mathrm{g} / \mathrm{ml} \mathrm{CHX}(\mathrm{B})$ for the indicated lengths of time, and Western-blot analysis was performed with antibodies against phospho-ERK1/2 (Thr202/Tyr204), phospho-JNK (Thr183/ Tyr185), or phospho-p38 (Thr180/ Tyr182). The ERK2, JNK, or p38 kinase was used as an internal control. Similar results were obtained in two other independent experiments.

$3 \mathrm{~B})$, suggesting that activation of the transcription factor Elk-1, but not of SRF, is responsible for SREmediated activation of egr-1 transcription by ANX.

\section{Anisomycin modulates multiple MAPK pathways}

Elk-1 is phosphorylated and activated by multiple MAPK pathways in response to a variety of extracellular stimuli (Janknecht et al., 1993). ANX has been shown to efficiently induce intracellular MAPK 
A

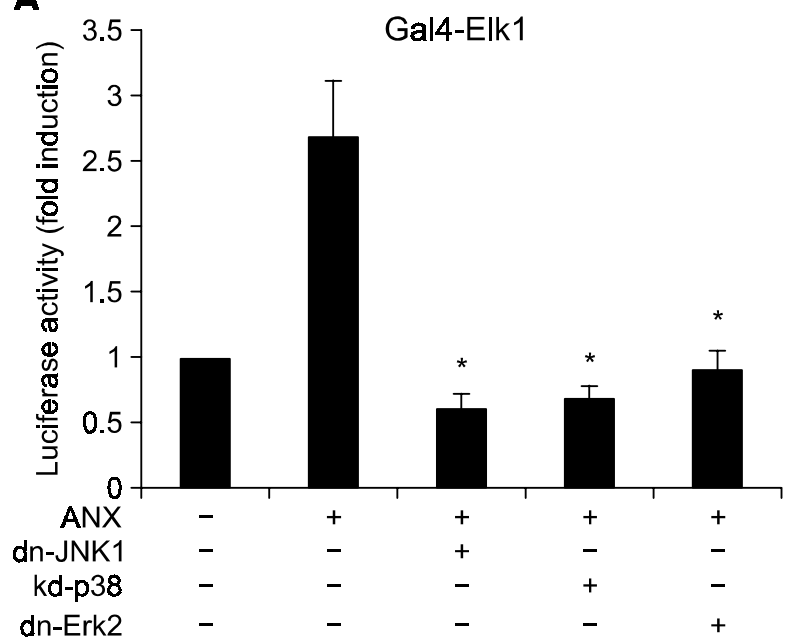

B

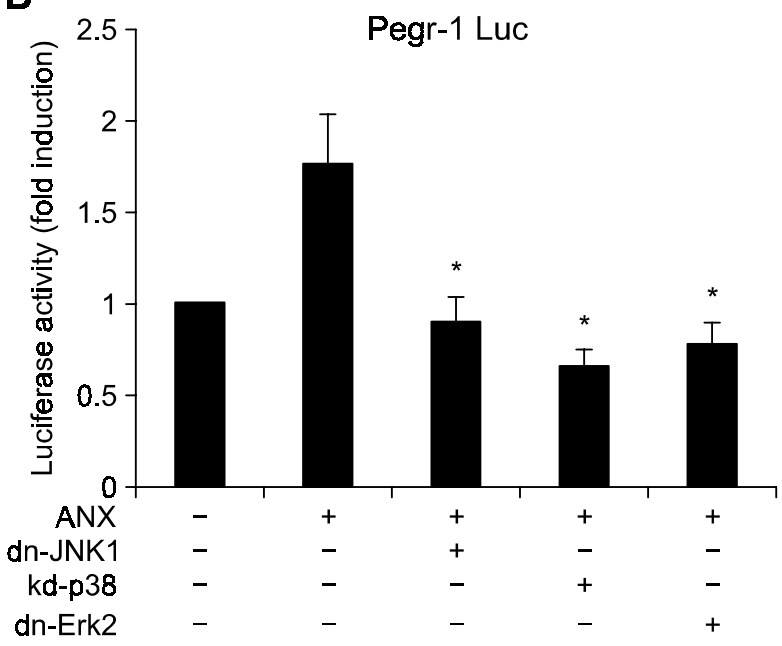

Figure 5. Multiple MAPKs are involved in ANX-induced transactivation of Elk-1 and activation of $\mathrm{P}_{\text {egr-1. }}$ U87MG cells were transfected with (A) plas-

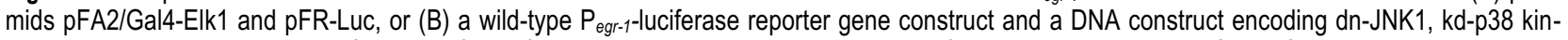
ase, or dn-ERK2, as indicated. After $24 \mathrm{~h}$ of transfection, the cells were treated with ANX for $6 \mathrm{~h}$ and then assayed for luciferase activity. The results are expressed as fold increase \pm S.D. of three independent experiments performed in triplicate, and are normalized for transfection efficiency using the $\mathrm{pCMV} / \beta$-gal reporter plasmid as a control. The statistical significance of the assay was evaluated using the Student's $t$-test $\left(^{*}, P<0.01\right.$ compared with untreated control cells).

signaling pathways that converge on Elk-1 activation, apparently independently of the ability of ANX to inhibit translation (Zinck et al., 1995). To confirm the possible regulatory relationship between MAPK pathways and Elk-1 transactivation by ANX, we measured the phosphorylation status of MAPK pathway proteins using phospho-specific antibodies. When serum-starved U87MG cells were treated with ANX, increases in the level of phosphorylation of ERK1/2, JNK1/2, and p38 MAPKs were detected within $0.5 \mathrm{~h}$ after stimulation, while total amounts of these MAPKs did not change (Figure 4A), suggesting that these MAPKs are activated by ANX. The effect of $\mathrm{CHX}$ on the phosphorylation of these MAPKs was comparable to that of ANX (Figure 4B).

ERK, JNK, and p38 MAPKs are involved in anisomycin-induced transactivation of Elk-1 and activation of the egr-1 promoter

To examine the possible involvement of different MAPK pathways in ANX-induced Elk-1 transactivation, Gal4-Elk-1/pFR-Luc trans-acting reporter constructs were transfected into U87MG cells along with plasmids encoding dn MAPKs. As shown in Figure 5A, ANX induction of Elk-1-dependent reporter gene expression was blocked by expression of dn-JNK1, kd-p38, or dn-ERK2 (Figure 5A). When we assessed the contribution of the different MAPKs to the ANX-induced transcriptional activity of $P_{\text {egr- } 1 \text {, we }}$ observed that expression of dn-JNK1, kd-p38, or
dn-ERK2 abolished the ability of ANX to enhance $P_{\text {egr-1 }}$ activity, as shown in Figure 5B.

The ERK, JNK, and p38 MAPK inhibitors prevent anisomycin-induced accumulation of Egr-1 protein To confirm that ERK1/2, JNK1/2, and p38 MAPKs contribute to ANX-induced Egr-1 expression, we examined the effect of pharmacological MAPK inhibitors on the accumulation of Egr-1. Western-blot analysis demonstrated that pretreatment with the MEK inhibitor U0126, the JNK inhibitor SP600125, and the p38 inhibitor SB202190 completely blocked the ANX-inducible accumulation of Egr-1 protein (Figure 6A). All of the MAPK inhibitors tested had a similar effect on $\mathrm{CHX}$-induced Egr-1 expression (Figure 6B), suggesting that multiple MAPK signaling pathways may play a role in ANX-induced activation of the egr-1 gene. Collectively, our results suggest that the protein synthesis inhibitors ANX and $\mathrm{CHX}$ stimulate Elk-1-mediated transcription of $P_{\text {egr-1 }}$ through multiple MAPK signaling pathways in U87 glioma cells.

\section{Discussion}

In this study, we examined the effects of the translation inhibitors ANX and $\mathrm{CHX}$ on the activation of Egr-1 expression. Our data indicate that ANX induces Elk-1 transactivation through all three major 
A

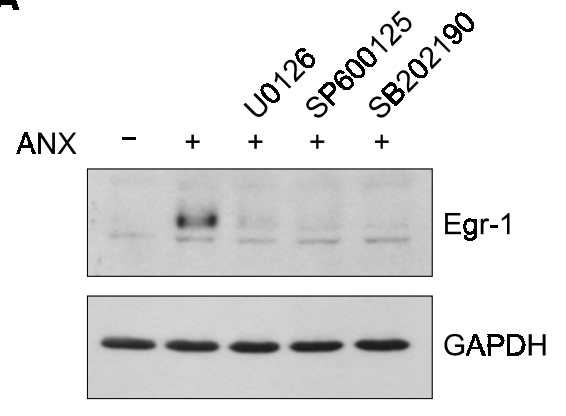

B

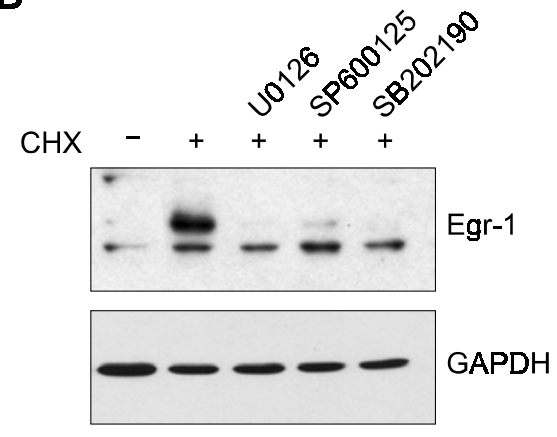

Figure 6. Effect of MAPK inhibitors on the ANX- and CHX-induced expression of Egr-1. Serum-starved U87MG cells were pretreated with U0126 $(50 \mu \mathrm{M})$, SP600125 (20 $\mu \mathrm{M})$, SB202190 $(10 \mu \mathrm{M})$, or no inhibitor for $1 \mathrm{~h}$, and were then treated with $10 \mathrm{ng} / \mathrm{ml}$ ANX (A) or $10 \mu \mathrm{g} / \mathrm{ml} \mathrm{CHX} \mathrm{(B)} \mathrm{for} 2 \mathrm{~h}$. Cells were then harvested, and Egr-1 expression was analyzed by Western blotting. GAPDH served as an internal control. Similar results were obtained in two other independent experiments.

MAPK pathways, including ERK, JNK, and p38 kinase, which in turn may play an important role in SRE-mediated egr-1 transcription.

Previous studies have demonstrated that immediate-early response genes like c-fos and egr-1 are hyper-induced when the cells are stimulated with growth factors in the presence of protein synthesis inhibitors (Cochran et al., 1984; Kruijer et al., 1984; Muller et al., 1984). We also have reported the results of nuclear run-on transcription experiments indicating that pretreatment with the protein synthesis inhibitor $\mathrm{CHX}$ causes a hyper-induction of growth factor-stimulated egr-1 transcription in rat 3Y1 fibroblasts (Shin et al., 2002). Thus, the existence of a labile transcription repressor that maintains immediate-early response genes in an inactive state has been proposed. According to this model, protein synthesis inhibitors block this short-lived repressor, causing hyper-induction of immediateearly response genes (Greenberg et al., 1986; Morello et al., 1990). Given that ANX stimulates c-fos gene expression through activation of MAPK signaling pathways independently of its ability to inhibit protein synthesis (Zinck et al., 1995; Barros et al., 1997), we tested whether these pathways are involved in the transcriptional activation of egr-1 by protein synthesis inhibitors in U87MG glioma cells.

In our experiments, we found that Egr-1 protein accumulated U87MG cells when the cells were treated with $\mathrm{CHX}$ or ANX, another translation inhibitor. Using serial mutations in $P_{\text {egr- } 1 \text {, we found that }}$ ANX reproducibly stimulated SRE-mediated transcription of egr-1 (Figure 2). The egr-1 SRE includes both a CArG box that binds the SRF, and an Ets motif that binds a TCF family member (Christy and Nathans, 1989; Watson et al., 1997). The ERK, JNK, and p38 MAPKs are responsible for Elk-1 phos- phorylation, which in turn correlates with increased transcription of egr-1 (Lim et al., 1998; Guha et al., 2001; Chen et al., 2004). Our data demonstrate that ANX rapidly stimulates phosphorylation of ERK, JNK, and p38 (Figure 4) and that Gal4-Elk1 transacting activity is stimulated by ANX (Figure 3), strengthening the hypothesis that Elk-1 plays a role in coupling $P_{\text {egr-1 }}$ to multiple MAPK signaling cascades. Therefore, our data indicate that the accumulation of Egr-1 protein induced by translation inhibitors occurs via positive regulation at the transcriptional level, mediated, at least in part, by activation of Elk-1. At present, unresolved question is how transfection with either one of dominant negative mutants of MAPKs, each of which blocks a specific MAPK signaling, is sufficient to cause complete shut-off of Elk-1 transactivation and egr-1 expression by ANX (Figure 5). One possible explanation is ERK, JNK and p38 pathways crosstalked each other and this cooperation might be critical for ANX-induced Elk-1 transactivation. This view is supported by the notion that MAPK pathways often shares upstream and downstream kinases and transcription factors that interact and integrate among different MAPK cascades (Cuschieri and Maier, 2005). Further study will be required to determine the detailed mechanisms underlying the regulation of ERK, JNK and p38 MAPK pathways by ANX.

Our data conflict with previous reports that ANX activates JNK and p38 MAPK, but does not activate ERK cascades (Hazzalin et al., 1998). In other studies, however, ANX-induced activation of the ERK1/2 signaling pathway was observed in MCAS cells (Konishi et al., 2004). These discrepancies may be attributable to the fact that the regulation of MAPK signaling pathways may differ in different cell 
lines.

The current data are not sufficient to evaluate the possible mechanisms by which ANX or CHX regulate MAPK activities. One possible explanation is that de novo expression of MAPK phosphatases such as MKP-1, which is required for down-regulation of MAPK, is sensitive to translation inhibitors. If the putative labile repressor responsible for the hyper-induction of immediate-early response genes by translation inhibitors does indeed exist, then it must be associated with the inactivation of MAPK signaling pathways. Alternatively, ANX or CHX may directly stimulate an upstream kinase of MAPKs, independently of inhibition of protein synthesis. Further experiments are required to fully understand the regulatory mechanism underlying the increased phosphorylation of MAPKs induced by ANX and $\mathrm{CHX}$.

In summary, this study demonstrate that ANX stimulates the trans-acting activity of Elk-1 in U87MG glioma cells via activation of the ERK1/2, JNK1/2, and p38 MAPKs, which leads to transcriptional activation of egr-1.

\section{Acknowledgment}

This work was supported by the Korea Research Foundation Grant (KRF-2003-041-E00051), and by grant (R01-2006-000-10950-0) from the Basic Research Program of Korea Science and Engineering Foundation.

\section{References}

Ahn BH, Min G, Bae YS, Bae YS, Min DS. Phospholipase D is activated and phosphorylated by casein kinase-II in human U87 astroglioma cells. Exp Mol Med 2006;38:55-62

Aicher WK, Sakamoto KM, Hack A, Eibel H. Analysis of functional elements in the human Egr-1 gene promoter. Rheumatol Int 1999;18:207-14

Barbacid M, Vazquez D. $\left({ }^{3} \mathrm{H}\right)$ anisomycin binding to eukaryotic ribosomes. J Mol Biol 1974;84:603-23

Baron V, Adamson ED, Calogero A, Ragona G, Mercola D. The transcription factor Egr1 is a direct regulator of multiple tumor suppressors including TGF $\beta 1$, PTEN, p53, and fibronectin. Cancer Gene Ther 2006;13:115-24

Barros LF, Young M, Saklatvala J, Baldwin SA. Evidence of two mechanisms for the activation of the glucose transporter GLUT1 by anisomycin: p38 (MAP kinase) activation and protein synthesis inhibition in mammalian cells. J Physiol 1997;504:517-25

Chen CC, Lee WR, Safe S. Egr-1 is activated by $17 \beta$-estradiol in MCF-7 cells by mitogen-activated protein kinase-dependent phosphorylation of ELK-1. J Cell Biochem 2004; 93:1063-74
Christner C, Wyrwa R, Marsch S, Kullertz G, Thiericke R, Grabley S, Schumann D, Fischer G. Synthesis and cytotoxic evaluation of cycloheximide derivatives as potential inhibitors of FKBP12 with neuroregenerative properties. J Med Chem 1999;42:3615-22

Christy B, Nathans D. Functional serum response elements upstream of the growth factor-inducible gene zif268. Mol Cell Biol 1989;9:4889-95

Clarkson RW, Shang CA, Levitt LK, Howard T, Waters MJ. Ternary complex factors Elk-1 and Sap-1a mediate growth hormone-induced transcription of egr-1 (early growth response factor-1) in 3T3-F442A preadipocytes. Mol Endocrinol 1999;13:619-31

Cochran BH, Zullo J, Verma IM, Stiles CD. Expression of the c-fos gene and of an fos-related gene is stimulated by platelet-derived growth factor. Science 1984;226:1080-2

Cuschieri J, Maier RV. Mitogen-activated protein kinase (MAPK). Crit Care Med 2005;33:S417-9

Dalton S, Treisman R. Characterization of SAP-1, a protein recruited by serum response factor to the $\mathrm{c}$-fos serum response element. Cell 1992;68:597-612

de Belle I, Huang RP, Fan Y, Liu C, Mercola D, Adamson ED. p53 and Egr-1 additively suppress transformed growth in HT1080 cells but Egr-1 counteracts p53-dependent apoptosis. Oncogene 1999;18:3633-42

Dieci G, Duimio L, Peracchia G, Ottonello S. Selective inactivation of two components of the multiprotein transcription factor TFIIIB in cycloheximide growth-arrested yeast cells. J Biol Chem 1995;270:13476-82

Edwards SA, Darland T, Sosnowski R, Samuels M, Adamson ED. The transcription factor, Egr-1, is rapidly modulated in response to retinoic acid in P19 embryonal carcinoma cells. Dev Biol 1991;148:165-73

Forsdyke DR. cDNA cloning of mRNAS which increase rapidly in human lymphocytes cultured with concanavalin-A and cycloheximide. Biochem Biophys Res Commun 1985;129: 619-25

Greenberg ME, Hermanowski AL, Ziff EB. Effect of protein synthesis inhibitors on growth factor activation of c-fos, c-myc, and actin gene transcription. Mol Cell Biol 1986;6:1050-7

Guha M, O'Connell MA, Pawlinski R, Hollis A, McGovern P, Yan SF, Stern D, Mackman N. Lipopolysaccharide activation of the MEK-ERK1/2 pathway in human monocytic cells mediates tissue factor and tumor necrosis factor alpha expression by inducing Elk-1 phosphorylation and Egr-1 expression. Blood 2001;98:1429-39

Hazzalin CA, Le Panse R, Cano E, Mahadevan LC. Anisomycin selectively desensitizes signalling components involved in stress kinase activation and fos and jun induction. Mol Cell Biol 1998;18:1844-54

Hipskind RA, Buscher D, Nordheim A, Baccarini M. Ras/MAP kinase-dependent and -independent signaling pathways target distinct ternary complex factors. Genes Dev 1994;8: 1803-16 
Hodge C, Liao J, Stofega M, Guan K, Carter-Su C, Schwartz J. Growth hormone stimulates phosphorylation and activation of elk-1 and expression of c-fos, egr-1, and junB through activation of extracellular signal-regulated kinases 1 and $2 . \mathrm{J}$ Biol Chem 1998;273:31327-36

Huang RP, Fan Y, de Belle I, Niemeyer C, Gottardis MM, Mercola D, Adamson ED. Decreased Egr-1 expression in human, mouse and rat mammary cells and tissues correlates with tumor formation. Int J Cancer 1997;72:102-9

Janknecht R, Ernst WH, Pingoud V, Nordheim A. Activation of ternary complex factor Elk-1 by MAP kinases. EMBO J 1993;12:5097-104

Kim SK, Choi JH, Suh PH and Chang JS. Pleckstrin homology domain of phospholipase C- $\gamma 1$ directly binds to $68-\mathrm{kDa}$ neurofilament light chain. Exp Mol Med 2006;38:265-72

Konishi Y, Sato H, Tanaka T. Anisomycin superinduces annexin $\mathrm{V}$ mRNA expression through the ERK1/2 but not the p38 MAP kinase pathway. Biochem Biophys Res Commun 2004;313:977-83

Krones-Herzig A, Adamson E, Mercola D. Early growth response 1 protein, an upstream gatekeeper of the p53 tumor suppressor, controls replicative senescence. Proc Natl Acad Sci USA 2003;100:3233-8

Kruijer W, Cooper JA, Hunter T, Verma IM. Platelet-derived growth factor induces rapid but transient expression of the c-fos gene and protein. Nature 1984;312:711-6

Lim CP, Jain N, Cao X. Stress-induced immediate-early gene, egr-1, involves activation of p38/JNK1. Oncogene 1998; 16:2915-26

Liu C, Rangnekar VM, Adamson E, Mercola D. Suppression of growth and transformation and induction of apoptosis by EGR-1. Cancer Gene Ther 1998;5:3-28

Liu C, Yao J, de Belle I, Huang RP, Adamson E, Mercola D. The transcription factor EGR-1 suppresses transformation of human fibrosarcoma HT1080 cells by coordinated induction of transforming growth factor-beta1, fibronectin, and plasminogen activator inhibitor-1. J Biol Chem 1999;274:4400-11

Liu C, Yao J, Mercola D, Adamson E. The transcription factor EGR-1 directly transactivates the fibronectin gene and enhances attachment of human glioblastoma cell line U251. J Biol Chem 2000;275:20315-23

Lopez M, Oettgen P, Akbarali Y, Dendorfer U, Libermann TA. $E R P$, a new member of the ets transcription factor/oncoprotein family: cloning, characterization, and differential expression during B-lymphocyte development. Mol Cell Biol 1994;14: 3292-309

Morello D, Lavenu A, Babinet C. Differential regulation and expression of jun, c-fos and c-myc proto-oncogenes during mouse liver regeneration and after inhibition of protein synthesis. Oncogene 1990;5:1511-9

Muller R, Bravo R, Burckhardt J, Curran T. Induction of c-fos gene and protein by growth factors precedes activation of c-myc. Nature 1984;312:716-20

Price MA, Rogers AE, Treisman R. Comparative analysis of the ternary complex factors Elk-1, SAP-1a and SAP-2 (ERP/NET). EMBO J 1995;14:2589-601

Ragione FD, Cucciolla V, Criniti V, Indaco S, Borriello A, Zappia V. p21Cip1 gene expression is modulated by Egr1: a novel regulatory mechanism involved in the resveratrol antiproliferative effect. J Biol Chem 2003;278:23360-8

Rao VN, Huebner K, Isobe M, ar-Rushdi A, Croce CM, Reddy ES. elk, tissue-specific ets-related genes on chromosomes $X$ and 14 near translocation breakpoints. Science 1989;244: $66-70$

Schratt G, Weinhold B, Lundberg AS, Schuck S, Berger J, Schwarz H, Weinberg RA, Ruther U, Nordheim A. Serum response factor is required for immediate-early gene activation yet is dispensable for proliferation of embryonic stem cells. Mol Cell Biol 2001;21:2933-43

Sharrocks $A D$. Complexities in ETS-domain transcription factor function and regulation: lessons from the TCF (ternary complex factor) subfamily. The Colworth Medal Lecture. Biochem Soc Trans 2002;30:1-9

Shin SY, Ko J, Chang JS, Min doS, Choi C, Bae SS, Kim MJ, Hyun DS, Kim JH, Han MY, Kim YH, Kim YS, Na DS, Suh PG, Lee $\mathrm{YH}$. Negative regulatory role of overexpression of PLC $\gamma 1$ in the expression of early growth response 1 gene in rat $3 Y 1$ fibroblasts. FASEB J 2002;16:1504-14

Sukhatme VP, Cao XM, Chang LC, Tsai-Morris $\mathrm{CH}$, Stamenkovich D, Ferreira PC, Cohen DR, Edwards SA, Shows TB, Curran T. A zinc finger-encoding gene coregulated with c-fos during growth and differentiation, and after cellular depolarization. Cell 1988;53:37-43

Thyss R, Virolle V, Imbert V, Peyron JF, Aberdam D, Virolle T. NF-kappaB/Egr-1/Gadd45 are sequentially activated upon UVB irradiation to mediate epidermal cell death. EMBO J 2005;24:128-37

Treisman R. Ternary complex factors: growth factor regulated transcriptional activators. Curr Opin Genet Dev 1994;4: 96-101

Tsai JC, Liu L, Guan J, Aird WC. The Egr-1 gene is induced by epidermal growth factor in ECV304 cells and primary endothelial cells. Am J Physiol Cell Physiol 2000;279: C1414-24

Virolle T, Adamson ED, Baron V, Birle D, Mercola D, Mustelin T, de Belle I. The Egr-1 transcription factor directly activates PTEN during irradiation-induced signalling. Nat Cell Biol 2001:3:1124-8

Watson DK, Robinson L, Hodge DR, Kola I, Papas TS, Seth A. FLI1 and EWS-FLI1 function as ternary complex factors and ELK1 and SAP1a function as ternary and quaternary complex factors on the Egr1 promoter serum response elements. Oncogene 1997;14:213-21

Zinck R, Cahill MA, Kracht M, Sachsenmaier C, Hipskind RA, Nordheim A. Protein synthesis inhibitors reveal differential regulation of mitogen-activated protein kinase and stressactivated protein kinase pathways that converge on Elk-1. Mol Cell Biol 1995;15:4930-8 